\title{
Brittle Failure of Inclined Key-hole Notches in Isostatic Graphite under in-Plane Mixed Mode Loading
}

\author{
P. Lazzarin', F. Berto ${ }^{1}$, M.R. Ayatollahi \\ ${ }^{1}$ Department of Management and Engineering - University of Padova Stradella S.Nicola \\ 3 - 36100 Vicenza (Italy). \\ ${ }^{2}$ Fatigue and Fracture Research Laboratory, Center of Excellence in Experimental Solid \\ Mechanics and Dynamics, School of Mechanical Engineering, Iran University of \\ Science and Technology, Narmak 16846, Tehran, Iran.
}

\begin{abstract}
Brittle fracture of isostatic graphite is studied experimentally and theoretically using plates containing key-hole notches subjected to different degrees of loading mixity. The main purpose of this paper is twofold. First, to provide a new set of experimental results on fracture of notched graphite samples, with different values of loading mixity and notch radii, which may be helpful for researchers because enlarges the very scarce available data; and second, to provide a fracture criterion for polycrystalline graphite under the above mentioned conditions. The averaged value of the strain energy density over a well-defined volume is used to predict the static strength of the considered specimens. Good agreement is found between the experimental data for the critical loads to failure and the theoretical predictions based on the constancy of the mean strain energy density over the material volume.
\end{abstract}

\section{INTRODUCTION}

Several researchers have studied in the past fracture resistance of polycrystalline graphite either under mode I (crack opening) or under mixed mode I/II (crack openingsliding) loading conditions. For example, Awaji and Sato [1] were among the earliest researchers who used the cracked Brazilian disk (CBD) specimen to study mixed mode I/II fracture toughness of two polycrystalline graphite materials experimentally. CBD is a test specimen of circular shape in which a centre crack is generated in order to measure fracture toughness of brittle materials. Yamauchi et al. [2, 3] also made use of disk type specimens (i.e. CBD specimen and semi circular bend (SCB) specimen subjected to three point bend loading) and investigated the mixed mode I/II fracture toughness of graphite. Other test specimens have also been used for exploring the fracture behavior of polycrystalline graphite materials. For instance, the single-edge notch bend specimen [4] and the three-point bend sandwiched specimen [5] are two other types of specimens used in the past for fracture testing on graphite. In another attempt, Etter et al. [6] investigated the mode I fracture toughness $K_{\text {Ic }}$ of isotropic polycrystalline porous graphite in addition to graphite/aluminum composite by means of 
the single-edge notched beam specimen. The extensive applications of graphite fibers in the composite materials (such as graphite/epoxy composites) have also prompted some researchers to study the fracture behavior of these materials under pure mode I and mixed mode I/II loading conditions [7-10].

Lomakin et al [11] made use of an energy release rate criterion for analyzing the fracture initiation in cracked graphite specimens under pure mode I loading. There are also several fracture criteria in literature for predicting the onset of mixed mode I/II brittle fracture in various engineering materials like graphite. The maximum tangential stress (MTS) criterion [12], the minimum strain energy density (SED) criterion [13] and the maximum energy release rate or G criterion [14] have been used more frequently by the researchers. Using a modified MTS criterion, Ayatollahi and Aliha [15] presented good estimates for the onset of mixed mode fracture in two grades of polycrystalline graphite containing sharp cracks.

Cracks are generated in graphite mainly because of the manufacturing faults or due to the coalescence of the micro-structural pores or defects that are inherently embedded in graphite. Whereas cracks are viewed as unpleasant entities in most engineering materials, nevertheless, notches of $\mathrm{U}$ or $\mathrm{V}$-shape are sometimes desired in design and manufacturing of products made from graphite. Graphite moulds, graphite heating elements and graphite chucks are only some examples for industrial components that contain $\mathrm{U}$ or $\mathrm{V}$-shape notches. A review of literature shows that in spite of extensive studies on mode I and mixed fracture in cracked graphite specimens, very few papers have dealt with brittle fracture in V-notched graphite components. Ayatollahi and Torabi [16] recently conducted a series of fracture tests on three different V-notched test specimens made of a polycrystalline graphite material. They also proposed a mean stress criterion and estimated their experimental results with very good accuracy. However, the results presented by Ayatollahi and Torabi [16] are confined only to pure mode I loading conditions. There are various practical conditions where the notches in graphite components are subjected a combination of tensile and shear deformation (or mixed mode I/II loading). In a recent paper, the present authors investigated mixed mode brittle fracture in polycrystalline graphite both experimentally and theoretically [17]. First a series of fracture experiments were conducted on centrally notched Brazilian disk specimens made of graphite to determine the fracture loads under different combinations of mode I and mode II loading. Then a theory based on the SED criterion [18-22] was employed to estimate the experimentally obtained fracture loads.

The main purpose of the present paper is to provide a new set of experimental results (70 new data) on fracture of graphite samples weakened by key-holes, with different values of loading mixity, inclination angles and notch radii, which may be helpful because enlarges the very scarce available data. By using the averaged value of the strain energy density over a well-defined volume, a fracture criterion for polycrystalline graphite under the above mentioned conditions is proposed to predict the static strength of the considered specimens. The third part of the paper deals with the analysis of fracture initiation direction and crack early propagation. 


\section{FRACTURE EXPERIMENTS}

The details of the graphite material, the test specimen and the fracture experiments are presented in this section.

\section{Material}

The fracture tests were conducted on a commercial isostatic polycrystalline graphite. The mean grain size was measured by using the SEM technique and the density was determined from the buoyancy method. The basic material properties of the tested graphite are listed in Table 1: mean grain size is $2 \mu \mathrm{m}$, porosity $7 \%$, bulk density of $1850 \mathrm{~kg} / \mathrm{m}^{3}$, mean tensile strength of $28.5 \mathrm{MPa}$, Young's modulus of $8.05 \mathrm{GPa}$ and shear modulus of $3.350 \mathrm{GPa}$. The compressive strength is equal to $110 \mathrm{MPa}$, whereas the flexural strength is $49 \mathrm{MPa}$.

All tests were performed under load control on a servocontrolled MTS axial testing device $\left( \pm 100 \mathrm{kN} / \pm 110 \mathrm{Nm}, \pm 75 \mathrm{~mm} / \pm 55^{\circ}\right)$. The load was measured by a MTS cell with $\pm 0.5 \%$ error at full scale.

Table 1. Mechanical properties

\begin{tabular}{|c|c|}
\hline Material Property & Value \\
\hline Elastic Modulus E [MPa] & 8050 \\
\hline Shear Modulus G [MPa] & 3354 \\
\hline Poisson's Ratio $v$ & 0.2 \\
\hline Ultimate Torsion Strength [MPa] & 30 \\
\hline Ultimate Compression Strength [MPa] & 110 \\
\hline Ultimate Tensile Strength [MPa] & 46 \\
\hline Fracture toughness $\left[\mathrm{MPa} \mathrm{m}{ }^{0.5}\right]$ & 1.06 \\
\hline Hardness [Shore] & 58 \\
\hline Density $\left[\mathrm{Kg} / \mathrm{dm}^{3}\right]$ & 1.85 \\
\hline Porosity [\%] & 7 \\
\hline Resistivity $[\mu \mathrm{ohm} \cdot \mathrm{m}]$ & 11 \\
\hline Thermal Conductivity $[\mathrm{W} /(\mathrm{m} \cdot \mathrm{K})]$ & 110 \\
\hline
\end{tabular}

\section{Geometry of the specimens}

As shown schematically in Fig. 1, the specimen used in the present investigation is a plate containing a central key-hole crack with a notch radius $\rho$ and the distance between the hole centres a. The specimen is subjected to tensile loading. By changing the angle $\beta$, different combinations of mode I and mode II (or tension and shear deformation) can be produced for key-holes. When the load is applied along the notch bisector (i.e. $\beta=0$ ), the key-holes are subjected to pure mode I deformation. By increasing the angle $\beta$ from zero, the loading condition changes from pure mode I towards mixed mode I+II. 

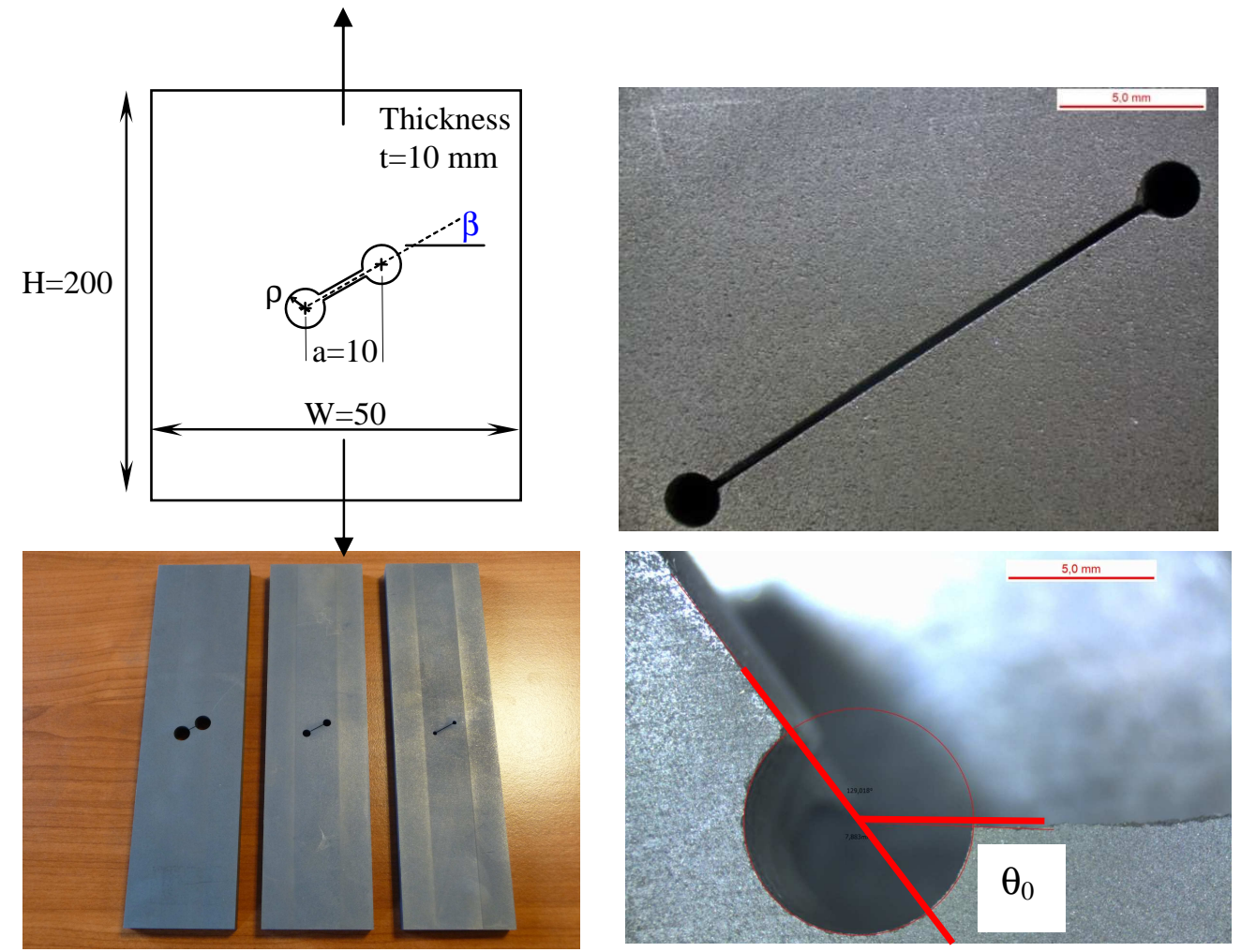

Figure 1. Geometry of the specimens (all dimensions in $\mathrm{mm}$ )

For all the tested graphite specimens, the width (W), the notch depth (a) and the thickness t were $50 \mathrm{~mm}, 10 \mathrm{~mm}$ and $10 \mathrm{~mm}$, respectively.

Five values of notch radius $\rho=0.25,0.5,1,2,4 \mathrm{~mm}$ were considered for manufacturing the test specimens so that the effects of the notch tip radius on mixed mode fracture of the graphite specimens are studied. With the aim to obtain different mode mixities, four values of the angle $\beta$ were considered $\left(\beta=0, \beta=30^{\circ}, \beta=45^{\circ}\right.$ and $\left.\beta=60^{\circ}\right)$.

In order to prepare the graphite test specimens, first several plates of $10 \mathrm{~mm}$ thick were cut from a graphite block. Then, the specimens were precisely fabricated by using a 2-D $\mathrm{CNC}$ water-jet cutting machine. Before conducting the experiments, the cut surfaces of the graphite specimens were polished by using a fine abrasive paper to remove any possible local stress concentrations due to surface roughness. A total number of 70 mixed mode I/II fracture tests were performed for various notch geometry parameters. For each geometry shape and loading angle, three separate fracture tests were performed by using a universal tension-compression test machine under displacement-control condition with a loading rate of $0.05 \mathrm{~mm} / \mathrm{min}$. The load-displacement curves recorded during the fracture tests were all linear and the specimens fractured suddenly. Therefore, the use of a brittle fracture criterion based on the linear elastic fracture mechanics (LEFM) is permissible. The mean values of fracture loads (F) recorded by the test machine are presented in Table 2, for each specimen. 
A review of Table 2 shows that the fracture load increases when the loading conditions change from pure mode $I(\beta=0)$ towards mixed mode I+II. Furthermore the fracture load enhances for larger notch tip radii, regardless of the mode mixity.

\section{SED CRITERION}

In order to estimate the fracture load in notched graphite components, engineers need an appropriate fracture criterion developed based on the mechanical behaviour of material around the notch tip. In this section, a strain-energy-density based criterion is described by which the fracture loads obtained from the experiments can be estimated very well.

The averaged strain energy density criterion (SED) as presented in Refs. [18-22] states that brittle failure occurs when the mean value of the strain energy density over a given control volume, $\bar{W}$, is equal to a critical value $W_{c}$. This critical value varies from material to material but is not dependent on the notch geometry and sharpness. The control volume is considered to be dependent on the ultimate tensile strength and the fracture toughness $K_{\mathrm{Ic}}$ in the case of brittle or quasi-brittle materials subjected to static loads.

Under plane strain conditions the critical length, $R_{c}$, can be evaluated according to the following expression [20]:

$$
\mathrm{R}_{\mathrm{c}}=\frac{(1+v)(5-8 \mathrm{v})}{4 \pi}\left(\frac{\mathrm{K}_{\mathrm{Ic}}}{\sigma_{\mathrm{t}}}\right)^{2}
$$

where $K_{\text {Ic }}$ is the fracture toughness, $v$ the Poisson's ratio and $\sigma_{\mathrm{t}}$ the ultimate tensile stress of a plain specimen that obeys a linear elastic behavior.

This critical value can be determined from the ultimate tensile stress $\sigma_{t}$ according to Beltrami's expression

$$
\mathrm{W}_{\mathrm{c}}=\frac{\sigma_{\mathrm{t}}^{2}}{2 \mathrm{E}}
$$

In parallel, the control volume definition via the control radius $\mathrm{R}_{\mathrm{c}}$ needs the knowledge of the fracture toughness $K_{\text {Ic }}$ and the Poisson's ratio $v$, see Eq. (1). The critical load that is sustainable by a notched component can be estimated by imposing $\bar{W}$ equal to the critical value $W_{c}$ which is considered here constant under mode I, mode II and in plane mixed-mode conditions. This assumption has been extensively verified for a number of different brittle and quasi-brittle materials [20-22].

As mentioned earlier, the properties of the graphite material used in the present investigation are: $\sigma_{\mathrm{t}}=46 \mathrm{MPa}, K_{\mathrm{Ic}}=1.0 \mathrm{MPa} . \mathrm{m}^{0.5}$, Poisson's ratio $v=0.2$. As a result, the critical SED for the tested graphite is $W_{\mathrm{c}}=0.13 \mathrm{MJ} / \mathrm{m}^{3}$ whereas the radius of the control volume is $R_{\mathrm{c}} \cong 0.17 \mathrm{~mm}$ considering realistic plane strain conditions.

Dealing with blunt notches under mixed mode loading, the problem becomes more complex than under mode I loading, mainly because the maximum elastic stress is out of the notch bisector line and its position varies as a function of mode I and mode II 
Table 2. Outline of theoretical and numerical parameters for the strain energy density evaluation for the tested graphite specimens

\begin{tabular}{cccccccc}
\hline $\begin{array}{c}\rho \\
{[\mathrm{mm}]}\end{array}$ & $\begin{array}{c}\beta \\
{\left[{ }^{\circ}\right]}\end{array}$ & $\begin{array}{c}\mathrm{a} \\
{[\mathrm{mm}]}\end{array}$ & $\begin{array}{c}\mathrm{F} \\
{[\mathrm{N}]}\end{array}$ & $\begin{array}{c}\mathrm{F}_{\text {th }} \\
{[\mathrm{N}]}\end{array}$ & $\begin{array}{c}\Delta \\
{[\%]}\end{array}$ & $\begin{array}{c}\sigma_{\max } \\
{[\mathrm{MPa}]}\end{array}$ & $\begin{array}{c}\text { SED } \\
{\left[\mathrm{MJ} / \mathrm{m}^{3}\right]}\end{array}$ \\
\hline 0.25 & 0 & 10 & 3967 & 4146 & 4.31 & 87.0 & 0.1201 \\
0.5 & 0 & 10 & 4060 & 4200 & 3.35 & 67.0 & 0.1225 \\
1 & 0 & 10 & 3998 & 4483 & 10.82 & 51.8 & 0.1044 \\
2 & 0 & 10 & 4967 & 5089 & 4.96 & 51.1 & 0.1251 \\
4 & 0 & 10 & 4910 & 5434 & 9.64 & 45.1 & 0.1070 \\
\hline 0.25 & 30 & 10 & 3991 & 3981 & 2.54 & 90.4 & 0.1317 \\
0.5 & 30 & 10 & 4022 & 4030 & 4.41 & 67.7 & 0.1308 \\
1 & 30 & 10 & 4125 & 4479 & 7.90 & 52.9 & 0.1111 \\
2 & 30 & 10 & 4609 & 5080 & 9.26 & 47.8 & 0.1079 \\
4 & 30 & 10 & 4775 & 5501 & 13.18 & 42.8 & 0.0991 \\
\hline 0.25 & 45 & 10 & 3786 & 3857 & 2.98 & 89.4 & 0.1264 \\
0.5 & 45 & 10 & 3893 & 4062 & 4.29 & 66.2 & 0.1205 \\
1 & 45 & 10 & 4121 & 4309 & 4.36 & 56.5 & 0.1200 \\
2 & 45 & 10 & 4972 & 5006 & 1.18 & 53.8 & 0.1293 \\
4 & 45 & 10 & 4777 & 5243 & 8.90 & 45.6 & 0.1090 \\
\hline 0.25 & 60 & 10 & 3995 & 4027 & 3.31 & 94.3 & 0.1291 \\
0.5 & 60 & 10 & 3856 & 4066 & 5.18 & 68.1 & 0.1179 \\
1 & 60 & 10 & 4114 & 4160 & 3.03 & 57.3 & 0.1283 \\
2 & 60 & 10 & 4496 & 4669 & 3.71 & 50.7 & 0.1215 \\
4 & 60 & 10 & 4553 & 5078 & 10.34 & 45.5 & 0.1055 \\
\hline
\end{tabular}

stress distributions. The maximum stress occurring along the edge of circular holes has been calculated numerically by using the FE code ANSYS $12.0^{\circledR}$. For each geometry, two models were created. The first model was mainly oriented to the determination of the point where the maximum principal stress and the maximum SED were located; the second model was more refined, with an accurate definition of the control volume where the strain energy density should be averaged. All the analyses have been carried out by using eight-node elements under the hypothesis of plane strain conditions.

Table 2 summarizes the outlines of the experimental, numerical and theoretical findings for the tested graphite specimens with four different inclination angles $\left(\beta=0^{\circ}, 30^{\circ}, 45^{\circ}\right.$, $60^{\circ}$ ), investigated in the present research. In particular, the table summarizes the theoretical $\left(F_{\text {th }}\right)$ and the mean experimental load to failure $(\langle F\rangle)$ for every loading angle $\beta$ and notch radius $\rho$. The Table also gives the maximum value of the principal stress $\left(\sigma_{\max }\right)$ and the SED value as obtained from the FE models of the graphite specimens by applying to the model the mean value of the critical loads. It is interesting to observe that the maximum principal stress along the notch edge is much greater (about two times) than the ultimate tensile stress of the material justifying the approach based on the average value of the SED over a control volume. 
As can be noted, the agreement between the experimental results obtained for the notched graphite specimens and the theoretical predictions based on a constant value of the local strain energy is satisfactory with a maximum relative deviation equal to $12 \%$.

\section{CRACK INITIATION ANGLES}

Dealing with crack initiation angles, they have been measured experimentally by using an optical microscope and a dedicate software called Las Leica Application Suite. The averaged value of the measured angles are compared in Table 3 with those obtained by numerical analyses identifying the point along edge where the SED and then the maximum stress reaches its critical value.

Table 3. Experimentally observed angles compared with numerical values

\begin{tabular}{cccc|cccc}
\hline $\begin{array}{c}\rho \\
{[\mathrm{mm}]}\end{array}$ & $\begin{array}{c}\beta \\
{\left[{ }^{\circ}\right]}\end{array}$ & $\begin{array}{c}\theta_{0, \text { FEM }} \\
{\left[{ }^{\circ}\right]}\end{array}$ & $\begin{array}{c}\theta_{0, \text { EXP. }} \\
{\left[{ }^{\circ}\right]}\end{array}$ & $\begin{array}{c}\rho \\
{[\mathrm{mm}]}\end{array}$ & $\begin{array}{c}\beta \\
{\left[{ }^{\circ}\right]}\end{array}$ & $\begin{array}{c}\theta_{0, \text { FEM }} \\
{\left[{ }^{\circ}\right]}\end{array}$ & $\begin{array}{c}\theta_{0, \text { EXP. }} \\
{\left[{ }^{\circ}\right]}\end{array}$ \\
\hline 0.25 & 30 & 37.1 & 36.5 & 0.25 & 60 & 67.3 & 64.3 \\
0.5 & 30 & 32.7 & 32.1 & 0.5 & 60 & 63.3 & 60.1 \\
1 & 30 & 30.9 & 36.1 & 1 & 60 & 61.6 & 63.7 \\
2 & 30 & 30.0 & 33.6 & 2 & 60 & 61.6 & 64.0 \\
4 & 30 & 30.0 & 31.2 & 4 & 60 & 60.0 & 58.0 \\
\hline 0.25 & 45 & 52.5 & 50.3 & & & & \\
0.5 & 45 & 50.0 & 54.9 & & & & \\
1 & 45 & 47.5 & 49.6 & & & & \\
2 & 45 & 46.2 & 49.1 & & & & \\
4 & 45 & 45.0 & 48.5 & & & & \\
\hline
\end{tabular}

\section{CONCLUSIONS}

The SED criterion was extended to rounded-tip notched domains in order to estimate the fracture load of notched graphite components. It was shown that the proposed method is suitable for the isostatic graphite stressed under mixed mode loading conditions, being the experimental results in good agreement with the results estimated by the SED approach. From the sound agreement between the theoretical and experimental results, it can be directly deduced that for the isostatic graphite the critical energy and the radius of the control volume are both constant material properties and independent of the loading mode, and can be simply evaluated from a pure mode I test.

\section{REFERENCES}

1. Awaji H, Sato S. Combined mode fracture toughness measurement by the disc test. J Engng Mater Tech 1978; 100; 175-2

2. Yamauchi Y, Nakano M, Kishida K, Okabe T. Measurement of fracture toughness for brittle materials under mixed mode impact loading using center-notched disk specimen. Zairyo /J Soc Mater Sci Japan 2000; 49(12); 1324-9 
3. Yamauchi Y, Nakano M, Kishida K, Okabe T. Measurement of mixed-mode fracture toughness for brittle materials using edge-notched half-disk specimen. Zairyo /J Soc Mater Sci Japan 2001; 50(3); 229- 4

4. Li M, Tsujimura M, Sakai M. Crack-face grain interlocking/bridging of a polycrystalline graphite: The role in mixed mode fracture. Carbon 1999; 37(10); 1633-9

5. Shi L, Haiyan L, Zhenmin Z, Fok ASL, Marsden BJ, Hodgkins A, Mummery PM., Marrow James. Analysis of crack propagation in nuclear graphite using three-point bending of sandwiched specimens. J Nuclear Mater 2008; 372; 141-51

6. Etter T, Kuebler J, Frey T, Schulz P, L"offler JF, Uggowitzer PJ. Strength and fracture toughness of interpenetrating graphite/aluminum composites produced by the indirect squeeze casting process. Mater Sci Engng A 2004; $386 ; 61-7$

7. Yum YJ, You H. Pure mode I, II and mixed mode interlaminar fracture of graphite/epoxy composite materials. J Reinforced Plastics Composites 2001; 20 (9); 794-08

8. Sukjoo C, Bhavani VS. Fracture toughness of transverse cracks in graphite/epoxy laminates at cryogenic conditions. Composites: Part B 2007; 38; 193-0

9. Wosu SN, Hui D, Dutta PK. Dynamic mixed-mode I/II delamination fracture and energy release rate of unidirectional graphite/epoxy composites. Engng Fract Mech 2005; 72; 1531-58

10. Jurf RA, Pipes RB. Interlaminar fracture of composite materials. J composite mater 1982 ; $16 ; 386-4$

11. Lomakin EV, Zobnin AI, Berezin AV. Finding the fracture toughness characteristics of graphite materials in plane strain. Strength Mater 1975; 7(4); 484-7

12. Erdogan F, Sih GC. On the crack extension in plates under plane loading and transverse shear. J Basic Engng, Trans of ASME 1963; 85; 519-5

13. Sih GC. Strain-energy-density factor applied to mixed mode crack problems. Int J Fract 1974; 10; 305-21

14. Hussain MA, Pu SL, Underwood J. Strain energy release rate for a crack under combined mode I and Mode II. Fracture Analysis, ASTM STP 560. (Philadelphia): American Society for Testing and Materials, 1974; 2-28

15. Ayatollahi MR, Aliha MRM. Mixed mode fracture analysis of polycrystalline graphite - A modified MTS criterion. Carbon 2008; 46; 1302-8

16. Ayatollahi MR, Torabi AR. Tensile fracture in notched polycrystalline graphite specimens. Carbon 2010; 48; 2255-65

17. Ayatollahi MR, Berto F, Lazzarin P. Mixed Mode Brittle Fracture of Sharp and Blunt Vnotches in Polycrystalline Graphite Carbon 2011; 49(7); 2465-74.

18. Lazzarin P, Zambardi R. A finite-volume-energy based approach to predict the static and fatigue behaviour of components with sharp V-shaped notches. Int J Fract 2001; 112; 275298.

19. Lazzarin P, Berto F. Some expressions for the strain energy in a finite volume surrounding the root of blunt V-notches. Int J Fract 2005; 135; 161-185.

20. Berto F, Lazzarin P. A Review of the volume-based strain energy density approach applied to V-Notches and Welded Structures, Theor Applied Fract Mech 2009; 52; 183-194.

21. Berto F, Lazzarin P, Gómez FJ, Elices M. Fracture assessment of U-notches under mixed mode loading: two procedures based on the equivalent local mode I concept. Int J Fract 2007; 148; 415-433.

22. Gómez FJ, Elices M, Berto F, Lazzarin P . Local strain energy to asses the static failure of U-notches in plates under mixed mode loading. Int J Fract 2007; 145; 29-45. 